\title{
Examining the Effective Social and Economic Factors on Underground Economy
}

\section{Somayeh Rasouli FiroozAbadi}

\author{
M.A. student of Economics \\ E mail: somayerasouli98@yahoo.com \\ Mohammad Javad Razmi \\ Associate Professor, Department of Economics, Ferdowsi University of Mashhad \\ Email: mirazmi@um.ac.ir \\ Mohsen Noghani Dokht Bahmani \\ Associate Professor, Department of Social Sciences, Ferdowsi University of Mashhad \\ Email: noghani@um.ac.ir
}

Doi:10.5901/mjss.2015.v6n3p525

\section{Abstract}

The expansion of underground economic activities is a reality in today's world and it plays a vital role in the economy and the lives of people in many countries. The aim of this study is to examine the effect of 8 variables (income level, education level of the individual, spouse's education, feeling of relative deprivation, unemployment, risk and severity of punishment, family background and the price gap between the formal and informal market) on the tendency of people to act in underground economy activities with a social and economic approach. Sistan and Baluchistan (eastern frontier province of Iran) is the case of this study with the sample size of 300 people. Logit model has been used to determine the people of two groups, which consist of people who act in underground activities and non engaged people. The results show that the unemployment and the feelings of relative deprivation in terms of social have a positive and significant effect on tendency of people to underground activities. But there are negative significant relationships between the level of individual spouse's education, the level of individual education, family background, income level and feeling of relative deprivation economically and the tendency of people to carry out activities in underground economy.

Keywords: Underground economy, Unemployment, Education, Logit, Relative deprivation

\section{Introduction}

Existence and development of shadow economy is a well-known fact in today's world. Some parts of economic activities are performed hide in all countries in order to evade the legal limitations. This indicates the importance and necessity of attention of policy makers to shadow economy. On the other hand, given that in many of the world shadow economy has a vital role in all aspects of economic, political and social life, understanding of the reasons of shadow economy is important.

Most societies attempt to control these activities through various measures such as punishment, prosecution, economic growth or education. Gathering statistics about who is engaged in underground (or criminal) activities, the frequency with which these activities occur, and the magnitude of such activities, is crucial for making effective and efficient decisions regarding the allocation of a country's resources. Given that the individuals who are engaged in these activities do not want to be identified, it is very difficult to get accurate information about underground activities. Hence, the estimation of shadow economy activities can be considered a scientific passion for knowing the unknown. Moreover, little is known about what motivates individuals to work in the shadow economy or request such work (Schneider et al., 2001).

Many studies have been conducted about the factors associated with the people tendency to the underground economy that mainly include evasion of taxes and regulations and economic exchanges. Unfair tax rates in the people views and difficult job requirements and the need to obtain a business license encourage people to underground economy. Given that most of the researches have been done in the macro perspective, it is not possible to know who are acting in underground economy. Therefore, if government wants to limit or eliminate various forms of hidden economy, it 
should investigate micro dimensions of hidden economy (Ryskavj, 1993). The studies about underground economy mainly focus on affecting economic factors on this phenomenon. Government failure in eliminating this part displays that an interdisciplinary approach is needed to analyze this phenomenon. Considering social factors in addition to economic factors affecting the tendency of people to underground activities can help to identify better the factors affecting the underground economy. This study seeks to address the social factors affecting the people tendency to act in underground economy, with emphasis on smuggling activities.

The concerns about underground economy will be encouraged experts to explore the issue of why people moved to work in the shadow economy. From this perspective, so the main objective of the current study is to examine the affecting social and economic factors on underground economy in Sistan and Baluchistan province in Iran.

\section{Concepts, Definitions and Generalities}

Many researchers have tried to present the complete definition for informal economy, never else there are still a lot of ambiguities about it and there are different understandings for it. There are various understanding but with much coordination between them.

Feige said that despite of determination of importance of underground activities, but there is still considerable ambiguity about the meaning of this issue. Different authors used various words that the plentifulness of these indicates commotion in its literature which tries to clear some undiscovered parts of it (Sameti and AlBooSoveilem, 2009).

Shakibaee (2007) defines shadow economy as an activity that includes production and distribution of all goods and services that are hidden from the eyes of the authorities knowingly or with other reasons.

Which activities are included in the definition of the underground economy affects the interpretation of any estimate of the extent of this phenomenon. For example, a very narrow definition would include only legal, market transactions that are not included in measured GDP. A somewhat broader definition would include both legal and illegal market transactions that are not included in measured GDP. One can also approach the above definitions by considering activity that is not detected by the tax authorities, rather than that omitted from GDP. Finally a very broad definition of the underground economy would be one that included all transactions, legal and illegal, market and non-market that are either intentionally excluded from GDP or omitted from the tax base (Tedds, 2004).

The informal sector, which produces legal goods but does not comply with government regulations, is a functioning part of all economies (Ihrig and Moe, 2003).

As a set of economic activities that takes place outside the framework of bureaucratic public and private sector establishments (Hart, 2008. cited, Elgin and Oyvat, 2013).

Definition is all currently unregistered economic activities that contribute to the officially calculated (or observed) Gross National Product (Schneider, 2005).

The System of National Accounts (SNA93) and the European System of National Accounts (ESA95) define the "Non observed economy", as all product activities that can be classified into the following three areas: (1) Underground production., (2) Informal production., (3) Illegal production (Dobre and Alexandru, 2009).

\subsection{Classification of Underground economy}

Economists provide different classification of informal economy. Some famous and comprehensive classification is done by Thomas, Feige and Khalatbari.

Thomas divided hidden economic activities, which he calls it informal economy, based on some of its attributions. Therefore, hidden economy (or informal economy) is divided into four household, informal, irregular and legal sectors.

Feige classified hidden economy in four categories of illegal, unreported, unregistered and informal economy through the new institutionalism perspective.

Khalatbari divided hidden economy into three sectors of black, self-serving and unorganized economy (Mir mohammadi, et al., 2007, p. 14).

Shadow or underground economic activity is a fact of life around the world, although a large literature exists on single aspects of the hidden economy, a current comprehensive survey is lacking (Schneider and Enste, 2000).

Tanzi (1999, Quotes Fleming, et al, 2000) notes that there cannot be any question that the underground economy is a real phenomenon with important implications that deserve attention and study." Of greatest concern is that this activity is unrecorded, and, as such, official national income accounts statistics do not accurately represent the true state of a nation's economy. Given that these Statistics are employed to generate economic policies; inaccurate figures may lead to inappropriate policy responses. 


\subsection{The causes of the underground economy}

The reasons for creating the underground economy are function of economic characteristics and situation. These characteristics are different from each economy to another one. Thus, the reasons of it are different in each situation (Sameti et al., 2009). The most important factors in the formation of shadow economy are as follow:

Tax and social security burdens, Intensity of regulation, Changes in labor market conditions and the employment system, Public Sector Services, Quality of Institutions, and Tax Morale. That Tax and social security burdens and Quality of Institutions are the most effective factors (Dell'Anno, 2007., Gomez and Pardo, 2007., Dreher and Schneider, 2009., Dreher et al., 2009., Schneider, 2010., Teobaldelli, 2011., Teobaldelli and Schneider, 2012., Kucera and Roncolato, 2008., Torgler and Schneider, 2009., Feld and Frey, 2007).

\subsection{The effects of the underground economy to the formal economy}

In order to study the effect of the shadow economy on the allocation of resources, several studies integrate underground economies into macroeconomic models. Development of the theoretical model of the business cycle as well as tax and monetary policy linkages with the shadow economy; on the one hand, the shadow economy's effect should be taken into account in setting tax and regulatory policies, and on the other hand, the existence of a shadow economy could lead to overstatement of the inflationary effects of fiscal or monetary stimuli (Schneider et al., 1989., Adam and Gins burgh, 1985).

Loayza (1996) presents a simple macroeconomic endogenous growth model which production technology depends on congest able public services. This model shows that making change in policy parameters and quality of public institutions lead to an increase in the relative size of shadow economy and result in lower economic growth rate.

There are different opinions in contrast with the advocate theories about the negative correlation between shadow and formal economy.

In the neoclassical view, the shadow economy is optimal in the sense that it responds to the economic environment's demand for urban services and small-scale manufacturing. From this point of view, the informal sector provides the economy with a dynamic and entrepreneurial spirit and can lead to more competition, higher efficiency and strong boundaries and limits for government activities.

The informal sector may offer great contributions "to the creation of markets, increase financial resources, enhance entrepreneurship, and transform the legal, social, and economic institutions necessary for accumulation. The voluntary self-selection between the formal and informal sectors, as described above in microeconomic models, may provide a higher potential for Economic growth and, hence, a positive correlation between an increase of the informal sector and economic growth (Nikopour et al., 2008).

Some specialists consider that the official activities of the underground economy provides flexibility and adaptability which it lacks, supplying areas that do not cover them, providing employment to the unemployed and acting as a remedy in times of recession. Milton Friedman said that the underground economy is a "safety valve" for the formal economy in crisis (Ramona Mara, 2011).

\section{Empirical Foundations}

\subsection{Poverty and underground economy}

Poverty and underground economy are serious problems with corrosive effects facing many countries. Poverty is currently one of the most serious problems in the World.

As poverty increases in countries of the world, there also appears a strong indication about the increasing rates of underground economy around the world. One therefore wonders whether there is a kind of linkage between the two concepts.

Poverty has been perceived by many as not just lack of money, food and assets but also as lack of access to education and health care and lack of security, dignity and independence (Elijah and Uffort, 2007).

Sen 1981 asserted that poverty is not only low income, but also deprivation of essential capabilities. The deprivation itself is a relative concept which can have different definitions in various places and times. Sen believed that relative deprivation is the core factor of poverty (Khodadad Kashy et al., 2002).

Elijah and Uffort (2007) study the relationship between poverty rates and size of underground economy in the developed and developing countries and exploring whether or not there is a link between them? The results of the 
descriptive analysis revealed that underground economy and poverty have no geographical boundary. The incidences of poverty and shadow economy are larger in the poor (developing and transition) countries when compared with the highly developed countries.

Dollar and Kraay (2002) they found that there is no difference between the income of the poor on average and that in rich countries and that policy-induced growth was as good for the poor as it was for the overall population.

\subsection{The relationship between unemployment and underground economy}

The question is that how changes in the unemployment rate affect the size and growth of underground economy? Not only from a business cycle perspective but also from the welfare public funding perspective assistance programmers (Bajada, 2005).

In the traditional theory of labour supply, individuals can merely spend their time at work and pursue leisure activities, according to their personal preference. In these models, there is no Differentiation between regular and illicit work. Becker (1965) extends the problem of efficient time allocation by the problem of deciding between different occupations. Thus, time is a scarce Good that has to be distributed optimally between work and leisure by the individual.

There are serious ambiguities about the trace direction unemployment factor on volume of black economy. In one hand, with increasing unemployment, the incentives of activity in informal economy increase, but in the other hand, it is said that unemployment rate is considered as a macroeconomic index and its increase is sign of starting the economic recession period and demand decrease for labor, in formal and informal activities. So it can expect decrease in black economy size with unemployment increase. Experimental results indicate that there is reverse relation between partnership rate and times works in informal part with formal part. one of the other results of these researches is very large negative elasticity between times work in informal economy and wage rate in governmental part and much mobility between parts (Sameti and AIBooSoveilem, 2009).

\subsection{The relationship between education and underground economy}

Informal economy is in relation with many factors. These factors which it is in relation with can be seen clearly in the reasons of informal economy. The factors which are in question can be listed as economic, social, ethical and political. Besides being affected by these factors, informal economy also affects certain factors. One of the factors which are mentioned is education (Buehn and Schneider, 2012).

The relationship between the level of education and informal economy is dual. While, the decrement of informal economy as the level of education rises and the decrement of the activities of underground economy through the decrement of crime rates can enable the dimension of informal economy to decrease, the existence of informal economy can cause the level of education to decrease especially because of children abandoning their education and doing informal activities. The fall of Education and the level of quality is one of the important reasons for informal employment and Including the risks that led to the tendency of people to underground activities due to lack of access to opportunities and skills will (Ela, 2013., Chen et al., 2002).

\section{Research Background}

Sameti et al (2010) examined the reasons of creating underground economy in Iran using multiply index method. The results show that unemployment, trade limitation, inflation, tax burden, revenue from natural resources are the most effective factors on forming underground economy in Iran. Then, using the Granger causality test, the causal relationship between underground economy and the informal economy has been tested. The relative size of this phenomenon increased during these 41 years. It started from 6.24 percent of formal economy in 1965 and reached to 5.50 percent in 1967 and 26.15 percent of formal economy in 2005. Average size of the underground economy during this period was 17.54 percent of formal economy. The results show that the underground economy in Iran mostly is the result of unemployment and trade limitations.

Emad Zadeh and Rafi'ei Tabatabaee (2010) in a study as " the analysis of the underground economy and the effective factors on it in some developed countries" found that in developed countries, age, gender, percentage of employment in the service sector, the general knowledge, self-assessment of tax system and the percentage of GDP have reverse relationship with the underground economy and percentage of employment in the agricultural sector, the marginal tax rate and the inflation rate have direct relationship with the underground economy.

Mousaaei and Ahmadzade (2010) examined the relationship between social education and smuggling in 
Hormozgan through qualified approach and found that family and peer education are effective factors on smuggling in micro- level and other factors like wealth seeking are effective in mid and macro levels.

Richardson (2006) The purpose of this study is to expand on the work of Riahi-Belkaoiu [Riahi- Belkaoiu, A. (2004). Relationship between tax compliance internationally and selected determinants of tax morale. Journal of International Accounting, Auditing and Taxation, 13, 135-143] and systematically investigate, on a cross-country basis, many of the key determinants of tax evasion identified by Jackson and Milliron [Jackson, B. R., \& Milliron, V. C. (1986). Tax compliance research: findings, problems and prospects. Journal of Accounting Literature, 5, 125-165]. Based on data from 45 countries; the results of the OLS regression analysis show that non-economic determinants have the strongest impact on tax evasion. Specifically, complexity is the most important determinant of tax evasion. Other important determinants of tax evasion are education, income source, fairness and tax morale. Overall, the regression results indicate that the lower the level of complexity and the higher the level of general education, services income source, fairness and tax morale, the lower is the level of tax evasion across countries. These findings remain robust to a broad range of cross-country control variables, an alternative tax evasion measure and various interactions.

Nikopour and Habibullah (2010) This study attempts to investigate the relationship between shadow economy and poverty by explaining the mechanism through which shadow economy affects poverty via its impact on government size and economic growth, and using the human poverty index (HPI) for developing and developed countries. In order to achieve this objective, the three- way interaction model is utilized using data of 139 developing and 23 developed countries separately during 1999-2007. For developing countries the dynamic panel system GMM and for developed countries, the fixed and random effects method of estimation is used. The results suggest that increasing the shadow economy leads to increase poverty in developing countries while it decreases poverty in developed countries.

Buehn and Farzanegan (2013) Using panel data for more than 80 countries from 1999-2007 this paper studies the marginal effect of education on the shadow economy, particularly considering the quality of institutions. The results show that higher levels of education fuel the shadow economy in an environment of weak political institutions.

\section{Shadow Economy Measurement}

Measuring and evaluating the causes and effects of shadow economy are very significant because it reveals the roots of many economic problems and communication channels of criminal acts against the law. Measurement methods of black economy and its relative issues have been classified in different ways. some researchers represented different classification due to data collection method, subject and the scope of review. Shadow economy is divided into 2 divisions based on measuring method: based on micro and macro levels and direct and indirect ways (Headquarters Fight Smuggling, Assistance Research and Statistics, 2009., Thomas et al., 1997).

Direct method is based field and survey studies in which questionnaires and interviews are used, and underground economy size is measured through direct and indirect reference (with electronic instruments like telephone, internet) to those who act in this field.

\section{Estimation Methodology}

With the development and application of complex methods such as linier regression, Logit and probit methods in the last decade and use of models based on neural networks, the accuracy of prediction increased to an acceptable level. Logit and probit models are used when dependent variable appears in two modes. The model that is used in this part is logit, which follows logistic regression. In logistic regression, such as multiple regressions, the coefficients of dependent variables are estimated. But their performance is different.

The smallest sum of squares is used in multivariable regression. In this method, the root mean square values between actual and predicted values of the dependent variable have been minimized. Thus, the curve is estimated based on the actual data (Sarai et al., 2011).

$$
\mathrm{Li}=\ln \left(\frac{p_{i}}{1-p_{i}}\right)=\mathrm{Z}_{\mathrm{i}}=\alpha+\beta \mathrm{X}_{\mathrm{i}}(1)
$$

The ratio of $\frac{p_{i}}{1-p_{i}}$ shows the chance of people of tendency to act underground activities and Li is the Logarithm of chance to linier parameters (Gujarati, 2005, p.708). 


\subsection{Variables explanation}

- Marital status: nominal variable with two options "single" and "married".

- Socio-economic status: in order to measure this item we used 3 variables in 3 levels: individual education, level of spouse education, income level. Education consists of years of formal education that consists of not educated to master degree and more. Monthly income is divided into 5 classifications.

- Unemployment: unemployment means the lack of income for the individual and his family. We can say that unemployment is the cause of crime. In fact, when unemployed person wants to meet needs the crime is increased (Rabyngn and Weinberg, 2004, p. 196).

- Sense of relative deprivation: relative deprivation is a condition in which person is not satisfied, the reason is that the person's expectations of themself are more. Also, the comparison that person make between himself and others enhance this feeling (Hussein Zadh et al., 2011). To measure this variable, 13 items are included in the questionnaire.

- Family background of underground activities: This variable is measured at nominal level and fitted with the following questions.

Do you have a background of family members and relatives in doing underground activities?

How much your tendency (no tendency) to underground activities is affected by relatives or friends?

- Risk and severity of punishment of underground activities:

When the expected utility of criminal activity is more than the utility of doing activity over the time, the person commits the crime. The probability of a crime is a function of penalty, the probability of conviction and other variables like available income in legal and illegal activities (SoltaniTiran, 1999).

Generally, how much the cost of smuggling is lower, people feel less risk and do this act at lower cost (KhezrZadeh et al., 2010).

- The difference between formal and informal market price:

High rate of tariff cause the price difference between internal and international markets that increase the motivation of importing goods through smuggling. The paperwork for export and import of goods causes costly legal procedure that can be a factor to do smuggling. Such a situation cause legal importers to smuggle in order to prevent losses in competitive market and shorten the path of importing goods (KhezrZadeh et al., 2010).

According to the mentioned variables, 8 hypotheses about tendency to underground activity are as follows:

1. There is negative and significant relationship between income levels and tendency to underground economy activities.

2. There is negative and significant relationship between the level of individual education and their tendency to perform activities in underground economy.

3. There is negative and significant relationship between level of spouse education and activity in underground economy.

4. There is negative and significant relationship between the amount of the penalty for underground activities and tendency to act in underground economy.

5. There is positive and significant relationship between the background of family in underground activities and tendency of people to perform these actions.

6. There is positive and significant relationship between the feeling of deprivation and the tendency of people to carry out activities in underground economy.

7. There is positive and significant relationship between unemployment among people and tendency to perform activities in underground economy.

8. There is positive and significant relationship between the difference between formal and informal market price and the tendency of people to act in underground activities.

\subsection{Population, sample size and sampling method}

This study includes two populations. First group consists of people who act in underground activities and the second group consists of people who do not act in this activities. Two researchers made questionnaires have been used for comparing these two groups. Sample size is 300 that were obtained through Cochran formula in which Z is equal to 1.96 and 0.07 and ${ }^{\boldsymbol{\delta}} 0.66$. Sample size in each group is 150 people.

In this study, purposive and convenience sampling was used. The purposive sampling selects people who have a 
lot of information. It is clear that purposive sampling is not designed to meet community credit. In this method, the sample is not significantly representative of population, but it consists of person who has deep understanding of the subject (Gall et al., 1996, P. 365).

\subsection{Reliability}

The Cronbach's alpha is used for determining the reliability of questionnaire items. The value of Cronbach's alpha is 0.644 for feeling of deprivation index which indicates the internal consistency.

\subsection{Validity}

Factor analysis has been used in order to evaluate the construct validity. Factor analysis is a powerful technique that is used in various sciences specially social sciences. This technique not only result in saving but also the researcher can use it to make index and reduce the data to a number of factors (Nazari and Mokhtari, 2009).

$\mathrm{KMO}$ statistic that indicates the accuracy of data for factor analysis and generalization of the result is about 0.741.Bartlett's test is 855.912 that confirm the suitability of data for factor analysis (Sangachin et al., 2012).

\section{Conclusion}

Used variables consist of context and economic variables as follows:

Children, F2 (feeling of relative deprivation index), Income, Unemployment, Marriage, Price (the gap between formal and informal market price), Risk (considered penalty for doing underground activities), Tend (children tendency to act in underground activities), Trend (individual tendency to do underground activity under the influence of family background).

Table 1: The results of logistic regression

\begin{tabular}{|c|c|c|c|}
\hline Variables & Coefficients & S.deviation & Prob \\
\hline C & 1.106 & 0.851 & 0.193 \\
\hline Children & 0.241 & 0.074 & $0.001^{*}$ \\
\hline $\mathrm{F} 2$ & -0.438 & 0.137 & $0.001^{*}$ \\
\hline Income & -0.278 & 0.131 & $0.033^{*}$ \\
\hline Unemployment & 0.202 & 0.114 & $0.069^{\star *}$ \\
\hline Marriage & -0.877 & 0.322 & $0.008^{*}$ \\
\hline Price & 0.335 & 0.123 & $0.076^{*}$ \\
\hline Risk & 0.006 & 0.099 & 0.951 \\
\hline Trend & -0.421 & 0.117 & $0.000^{*}$ \\
\hline \multicolumn{4}{|c|}{$\begin{array}{l}\text { McFadden R- squared= } 0.149 \\
\text { Log likelihood= }-176.91\end{array}$} \\
\hline
\end{tabular}

Description: Symbols * and ** indicate significance levels, respectively, 5\% and 10\%.

\section{Source: Research calculation}

Table 1 shows, relative deprivation economically index has negative and significant relationship with tendency to act in underground activities. With an increase in the sense of relative deprivation in terms of economic potential zero group (people who do not active in the underground economy) tendency to group 1 (active participants in the underground economy) was reduced that is not in accordance with the theoretical bases. Without considering the amount of relative deprivation, this people compare themselves with peers and ignoring their abilities lead to the creation of higher relative deprivation. Since the person who acts in shadow economy may be neglected by others. So the possibility of action in underground activity is reduced and other factors such as education, job, gender, married Status and number of children have influence.

Income level has negative relationship with underground economy. With an increase in income level the likelihood of individual tendency to act in underground activity will be reduced. Several factors contribute to a person's activity in shadow economy such as: 
Statement of income: suppliers in shadow economy compare their income with their neighbors, want to have a better life, thus, it increases the shadow economy activities. So, the positive correlation seems plausible.

People who need to have more disposable income for use in a particular situation (e.g., construction of houses, celebrations, etc.) are more likely to be involved in the activities of the shadow economy (Schneider et al., 2001).

On the one hand, as illegal activities are hidden from government regulators' view, these items are not reported in collected information. Given that people who engage in this activity do not want to be known, obtaining detailed information about the underground activities particularly income level of actors is very difficult.

The unemployment rate (rate of access to legal jobs) has significant and positive relationship with tendency to underground activities. with an increase in unemployment rate the likelihood of individuals to move from zero group to group 1(people who act in underground economy) is increased. Accessing to the desired job is one of the basic needs of a person. With an increase of unemployment, the motivation for acting in informal economy is increased. One the other hand, unemployment rate is considered as macro economy index and its increase displays the beginning of recession and reduction of demand for acting in formal and informal economies. Strict regulations and wage issues are the reasons for informal economy mobility.

Price differentiation in formal and informal markets has a positive relationship with tendency of people to act in underground activities. With an increase in price gap the tendency of zero group to group 1 will increase.

The risk and severity of punishment did not have any influence on tendency of people to carry out activities in underground economy in this model.

Used variables in second model include social and cultural variables such as:

F3 (the index of relative social and cultural deprivation), Trend (the tendency of people to act in underground activities under the influence of family background), Education (education level of active or passive people in underground economy), Sped (spouse educational level of active or passive people in underground economy), Background.

Table 2: The results of logistic regression

\begin{tabular}{|c|c|c|c|}
\hline Variables & Coefficients & S.deviation & Prob \\
\hline C & 6.360 & 1.157 & 0.000 \\
\hline F3 & 0.704 & 0.201 & $0.000^{*}$ \\
\hline education & -0.482 & 0.231 & $0.037^{*}$ \\
\hline sped & -0.579 & 0.198 & $0.004^{*}$ \\
\hline Trend & -0.469 & 0.164 & $0.037^{*}$ \\
\hline background & -0.825 & 0.396 & \\
\hline $\begin{array}{l}\text { McFadden R- squared= } \\
\text { Log likelihood= -90.33 }\end{array}$
\end{tabular}

Description: Symbols * and ** indicate significance levels, respectively, 5\% and 10\%.

Source: Research calculation

As it is considered in this model, table 2 shows that relative deprivation index from cultural and social views has positive and significant relationship with people's tendency to act in underground economy. With an increase in relative deprivation index the tendency from zero groups to act in underground activities will increase. Relative deprivation shows individual feeling that lacks competency. The criteria for this person is to reference to others. This index includes family relations, reliability to others, educational situation and accessibility to education facilities.

Education level of the individual and the spouse's education level have negative relationship with the tendency of people to carry out activities. With the increase of educational level the tendency of people to carry out underground activities will be reduced.

The tendency of people to act in underground economy is under the influence of family background and family background has negative effects on people tendency to act in underground activities.

Considering that there are no theoretical backgrounds in this field, data collected, comparing two groups' average and higher educational level of people who are not active display that family background did not have influence on people tendency to act in underground activities.

McFadden statistics in two estimated models are about 0.149 and 0.331 respectively. Louviere (2000) stated that McFadden statistic must be above 0.1 and the amount of it between 0.2 and 0.3 is in accordance with the adjustment 
coefficient of R2 least squares (OLS) in 0.7 to 0.9 intervals. In consistent with what Louviere has already stated the results of the model is acceptable (Sharzei and Javidi, 2011).

\section{References}

Adam, M. C. and Ginsburgh, V., 1985, 'The effects of irregular markets on macroeconomic policy: some estimates for Belgium', European Economic Review, 29, 1, pp. 15-33.

Bajada, C., 2005, 'Unemployment and the underground economy in Australia', Applied Economics, 37, 2, pp. 177- 189.

Becker, G- S., 1965, 'A Theory of the Allocation of Time', The Economic Journal, 75, 299, pp. 493- 517.

Buehn, A. and Farzanegan, M. R., 2013, 'Impact of education on the shadow economy: Institutions matter', Economics Bulletin, 33, 3, pp. 2052- 2063.

Buehn, A. and Schneider, F., 2012, 'Shadow economies around the world: novel insights, accepted knowledge, and new estimates', International Tax and Public Finance, 19, 1, pp. 139-171.

Chen, M. A., Jhabvala, R. and Lund, F., 2002, 'Supporting workers in the informal economy: a policy framework Geneva', International Labour Office.

Dell'Anno, R., Gómez-Antonio, M. and Pardo, A., 2007, 'The shadow economy in three Mediterranean countries: France, Spain and Greece. A MIMIC approach', Empirical Economics, 33,1, pp. 51- 84.

Dobre, I. and Alexandru, A., 2009, 'The impact of unemployment rate on the dimension of shadow economy in Spain: A Structural Equation Approach', European Research Studies Journal, 13, 4, pp. 179-197.

Dollar, D. and Kraay, A., 2002, 'Growth is Good for the Poor', Journal of economic growth, 7, 3, pp. 195-225.

Dreher, A. and Schneider, F., 2010, 'Corruption and the shadow economy: an empirical analysis', Public Choice, 144, 1-2, pp. 215-238.

Dreher, A., Kotsogiannis, C. and Mccorriston, S., 2009, 'How do institutions affect corruption and the shadow economy?', International Tax and Public Finance, 16, 6, pp.773-796.

Ela, M., 2013, 'An Assessment on the Relationship between Informal Economy and Educational Level in Turkey', International Journal of Economics and Financial Issues, 3, 4, pp. 910-922.

Elgin, C. and Oyvat, C., 2013, 'Lurking in the cities: Urbanization and the informal economy', Structural Change and Economic Dynamics, 27, pp. 36-47.

Elijah, O. A. and Uffort, L, 2007,' Comparative analysis of the relationship between poverty and underground economy in the highly developed, transition and developing countries'.

Emadzade, M. and Rafi'eiTabatabaee, Z., 2010, 'Analysis of the underground economy and the factors influencing the selection of the developed countries', Journal of Macroeconomics Journal, 7, 13, pp. 85-96.

Feld, L.P. and Frey, B.S., 2007,'Tax Compliance as the Result of a Psychological Tax Con-tract: The Role of Incentives and Responsive Regulation', Law and Policy 29/1, pp. 102-120.

Gal, M., Borg, W. and Gal, J., 1996, 'Qualitative and quantitative research methods in education and psychology', cover 1, (Translation: A. Nasr et al), Tehran: Research organizations and universities Humanities Books Editor: Shahid Beheshti University.

Gujarati, D., 2005, 'Basic Econometrics' (Translation: H. Abrishami), Tehran, Institute Publications and Print Tehran University, 2004, cover 2.

Headquarters Fight Smuggling, Assistance Research and Statistics, 2009, Overview of methods Calculate the hidden economy and its dimensions, Publication Series Hidden economy, 1, pp. 11-28.

Hussein Zadh, A-H., Navah, A. and Anbari, A., 2011, 'Sociological study of factors affecting the tendency to quarrel mass (Case Study Ahwaz)', Security Knowledge, 13, 2, pp. 191-225.

Ihrig, J. and Moe, K. S., 2004, 'Lurking in the shadows: the informal sector and government policy', Journal of Development Economics, 73, 2, pp. 541-557.

Khezerzade, A., Soliemani, M. and Razavian, M., 2010, 'Check smuggling of southern maritime borders Iran', Journal of Applied Geographical Sciences, Cover 15, 18, pp. 67-84.

Khodadad Kashy, F., Bagheri, F., Haider, kh. and Khodadad Kashy, O., 2002, 'Measurement of poverty in Iran, Poverty gap, Poverty Index, The potential of the poverty line 1984-2000', Group of economic statistics.

Kucera, D. and Roncolato, L., 2008, 'Informal employment: Two contested policy issues', International Labour Review, 147, 4, pp. 321 348.

Loayza, N. V., 1996, 'The economics of the informal sector: a simple model and some empirical evidence from Latin America', In Carnegie-Rochester Conference Series on Public Policy , 45, pp. 129-162, North-Holland.

Mara, E. R., 2011, 'Causes and consequences of underground economy', Anale. Seria Ştiinţe Economice. Timişoara, (XVII), pp. 11091116.

Mir mohammadi, M., Barite, M. and Parkhide, A., 2007, 'Recognition of nature's hidden economy', Tehran: Research tadber Economy, pp.53-68.

Mousaaei, M. and AhmadZadeh, M., 2010, 'Study of Relationship Community Education and committing smuggling in the province Hormozgan', Institute for TRADE STUDIES AND RESEARCH, 43, pp. 69-77.

Nikopour, H. and Habibullah, M- S., 2010, 'Shadow Economy and Poverty', MPRA Paper, 23599, pp. 1-26.

Nikopour, H., Habibullah, M- S. and Schneider, F., 2008, 'The shadow economy Kuznets's curve panel data analysis', Munich Personal RePEc (MPRA), Paper, 12956. 
Rabyngn, E. and Weinberg, M., 2004, 'Seven theoretical perspectives on social issues', (Translation: R. Sadiq Savenstani), Tehran: Institute of Tehran University Press.

Richardson, G., 2006, 'Determinants of tax evasion: A cross-country investigation', Journal of International Accounting, Auditing and Taxation, 15(2), pp. 150-169.

Ryskavj, R., 1993, 'Take the hidden economy and its share in a developed economy (What we know, what we do not know) and what we do for it', (Translation: K. Sphere), Journal of the ravand, 14\& 15, pp. 132- 152.

Sameti, M. and AlBooSoveilem, M., 2009, 'Impact Participation Rate and Unemployment Rateon Underground Economy in OECD Countries', Journal of Quantitative Economics, summer 2009, 6, 2, pp. 63-88.

Sameti, M., Sameti, M. and DalaiMilan, A., 2009, 'Estimates of the underground economy in Iran (2005-1965) the method MIMIC', International Economics Studies, 20, 35, pp. 89-114.

Sangachin, F., Salehi, A. and Dinarvand, M., 2012, 'Assess the level of development of the country by a factor analysis approach', Town And Country Planning, 4, 2, pp. 26-5.

Sarai, M., Sorkhkamal, k., ByranVndzadh, M. and Mahinizadh, M., 2011, 'Evaluation of development provinces using techniques Logit and probit', Quarterly Journal of Human Geography, 3, 3, pp. 80-92.

Schneider, F., 2005, 'Shadow economies around the world: what do we really know?', European Journal of Political Economy, 21, 3, pp. 598-642.

Schneider, F., 2010, 'The Influence of Public Institutions on the Shadow Economy: An Em-pirical Investigation for OECD Countries', European Journal of Law and Economics, 6/3, pp. 441-468.

Schneider, F. and Enste, D-H., 2000, 'Shadow Economies: Size, Causes, and Consequences', Journal of Economic Literature, XXXVIII, pp. 77-114.

Schneider, F., Braithwaite, V. and Reinhart, M., 2001, 'Individual behaviour in the cash/shadow economy in Australia: Facts, empirical findings and some mysteries', Working Paper, Department of Economics, Johannes Kepler University of Linz, 0107.

Schneider, F., Hofreither, M. F. and Neck, R., 1989, 'The consequences of a changing shadow economy for the "official" economy: some empirical results for Austria', Springer Berlin Heidelberg, pp. 181-211.

Sharzei, g-a. and Javidi, n., 2011, 'Internalize external costs of electricity generation test method selection', Quarterly Energy Economics Review, 29, pp. 1-30.

Shakibaee, A., 2007, 'Estimating the hidden economy (Shadow economy) Iran and the international comparison', Series of scientific meetings the hidden economy, First Book, Fifth meeting, Tehran Headquarters Fight Smuggling, Assistance Research and Statistics, pp. 41-52.

SoltaniTiran, F., 1999, 'Application Analysis Causal In social science research And Behavioral Along with the introduction of Software Lisrel', Tehran, Public Administration Training Centre, pp.140-190.

Thomas, J-J., Ryscavage, R. and Vincenzo, S., 1997, 'Informal economy', Monetary \& Banking Research Institute, pp. 152-161.

Tedds, L- M., 2004, 'The Underground Economy in Canada', MPRA Paper, 4229.

Teobaldelli, D., 2011, 'Federalism and the shadow economy', Public Choice, 146, 3-4, pp. 269-289.

Teobaldelli, D. and Schneider, F., 2012, 'Beyond the veil of ignorance: The influence of direct democracy on the shadow economy', CESifo Working Paper MO3749, University of Munich, Munich.

Torgler, B. and Schneider, F., 2009, 'The impact of tax morale and institutional quality on the shadow economy', Journal of Economic Psychology, 30, 2, pp. 228-245. 